\title{
Integration and bioinformatics analysis of DNA-methylated genes associated with drug resistance in ovarian cancer
}

\author{
BINGBING YAN $^{1 *}$, FUQIANG YIN ${ }^{2,3^{*}}$, QI WANG $^{1}$, WEI ZHANG ${ }^{1}$ and LI LI ${ }^{1,3}$ \\ ${ }^{1}$ Department of Gynecologic Oncology, Affiliated Tumor Hospital of Guangxi Medical University; \\ ${ }^{2}$ Medical Scientific Research Centre, Guangxi Medical University, Nanning, Guangxi 530021; ${ }^{3}$ Key Laboratory of \\ High-Incidence Tumor Prevention and Treatment, Guangxi Medical University, \\ Ministry of Education, Nanning, Guangxi 530021, P.R. China
}

Received December 14, 2014; Accepted November 27, 2015

DOI: $10.3892 / \mathrm{ol} .2016 .4608$

\begin{abstract}
The main obstacle to the successful treatment of ovarian cancer is the development of drug resistance to combined chemotherapy. Among all the factors associated with drug resistance, DNA methylation apparently plays a critical role. In this study, we performed an integrative analysis of the 26 DNA-methylated genes associated with drug resistance in ovarian cancer, and the genes were further evaluated by comprehensive bioinformatics analysis including gene/protein interaction, biological process enrichment and annotation. The results from the protein interaction analyses revealed that at least 20 of these 26 methylated genes are present in the protein interaction network, indicating that they interact with each other, have a correlation in function, and may participate as a whole in the regulation of ovarian cancer drug resistance. There is a direct interaction between the phosphatase and tensin homolog (PTEN) gene and at least half of the other genes, indicating that PTEN may possess core regulatory functions among these genes. Biological process enrichment and annotation demonstrated that most of these methylated genes were significantly associated with apoptosis, which is possibly an essential way for these genes to be involved in the regulation of multidrug resistance in ovarian cancer. In addition, a comprehensive analysis of clinical factors revealed that the methylation level of genes that are associated with the regulation of drug resistance in ovarian cancer was significantly correlated with the prognosis of ovarian cancer. Overall, this study preliminarily explains the potential correlation between the genes with DNA methylation and drug resistance in ovarian
\end{abstract}

Correspondence to: Professor Li Li, Department of Gynecologic Oncology, Affiliated Tumor Hospital of Guangxi Medical University, 71 Hedi Road, Nanning, Guangxi 530021, P.R. China E-mail: lili@gxmu.edu.cn

*Contributed equally

Key words: DNA methylation, ovarian cancer, drug resistance, bioinformatics cancer. This finding has significance for our understanding of the regulation of resistant ovarian cancer by methylated genes, the treatment of ovarian cancer, and improvement of the prognosis of ovarian cancer.

\section{Introduction}

Ovarian cancer is a malignant tumour posing a serious threat to women's health. As the main type of ovarian cancer, ovarian epithelial carcinoma accounts for $85-90 \%$ of all ovarian cancers. The mortality rate of ovarian epithelial carcinoma ranks first among all female reproductive tract malignancies. Approximately $70 \%$ of ovarian cancer patients are in the late stage when diagnosed. Most of these tumours easily develop drug resistance in the course of post-surgery chemotherapy; therefore, the therapeutic effect is greatly reduced, leading to a survival rate of just $30 \%$ for ovarian cancer (1). Therefore, multidrug resistance is the main cause of ovarian cancer chemotherapy failure. Studies have demonstrated that multidrug resistance is the result of multiple genes or proteins and a multistep process, or cross-reactivity of multiple factors. Multidrug resistance involves several different regulatory mechanisms, and epigenetic regulation is one of the significant regulatory mechanisms in the development of ovarian cancer multidrug resistance (2). Epigenetic modification is a heritable change in gene expression without a DNA sequence change (3). Epigenetic modification includes DNA methylation, histone modification, chromatin modification and microRNA modification (4), and plays an essential role in gene transcription regulation. As one of the main pathways of epigenetic regulation, DNA methylation is closely related to the multidrug resistance, development, progression, clinical diagnosis and prognosis of ovarian cancer (5). Therefore, a comprehensive study of the mechanisms of ovarian cancer has crucial diagnostic and therapeutic significance.

DNA methylation is the process by which a methyl group from the donor S-adenosyl-L-methionine is added to the 5-carbon position of cytosine to form 5-methylcytosine under the catalysis of DNA methyltransferase (DNMT). DNA methylation includes whole-genome hypomethylation and $\mathrm{CpG}$ island hypermethylation of a promoter region. $\mathrm{CpG}$ island hypermethylation may lead to decreased or even silenced gene 
expression levels and eventually plays a significant role in the regulation of cancers, including ovarian cancer (6). It has been proven that DNA methylation plays a critical role in the regulation of multidrug resistance in ovarian cancer. Therefore, in this study, we systematically analysed 26 methylated genes that have significant regulatory roles in multidrug-resistant ovarian cancer. We conducted an integrated analysis of their correlation with ovarian cancer clinical factors including malignant behaviour, prognosis and staging. Additionally, we investigated the relevance and integrity of these 26 genes through bioinformatics. This study has overall reference value and significance in the understanding of the regulatory mechanisms of ovarian cancer multidrug resistance by DNA methylation.

\section{Materials and methods}

Gene search. Using 'ovarian cancer' or 'ovarian carcinoma', 'DNA methylation' or 'methylation', 'resistant' or 'resistance' or 'chemoresistance' as key words, we screened methylated genes associated with the regulation of drug resistance in ovarian cancer from an advanced search in the PubMed database (http://www.ncbi.nlm.nih.gov/pubmed/).

\section{Bioinformatics analysis}

Biological process annotation and enrichment. We screened biological processes with significance $(\mathrm{P}<0.05)$ and involved genes through biological process gene annotation and enrichment analysis using the Database for Visualization and Integrated Discovery (DAVID) software (http://david.abcc. ncifcrf.gov/) (7) and Coremine medical software (http://www. coremine.com/).

Protein interactions. Protein interaction analysis was conducted using the search tool for the retrieval of interacting genes/proteins (STRING) and online software (http://string-db. org/) (8). The protein interaction reliability score was 0.400 (medium confidence).

\section{Results}

Comprehensive analysis of the regulation of ovarian cancer multidrug resistance by methylated genes. By fully integrating publication references for the association of DNA methylation with ovarian cancer multidrug resistance, we screened 26 methylated genes that are significantly related to ovarian cancer multidrug resistance; namely MLH1, BRCA1, FBXO32, DNAJC15, CSAG2, PROM1, ASS1, RASSF1, PTEN, TNFRSF10A, ABCG2, ZMYND10, MDR1, TGFBI, RGS10, UCHL1, Sulf-1, SFRP, MAL, TUBB3, L1TD1, CLDN4, HOXA10, HOXA9, HOXA11 and FANCF. With the exception of CSAG2, MDR1, TUBB3, L1TD1, FANCF and HOXA10, all of the genes were hypermethylated with low expression in drug-resistant tissues and cells of ovarian cancer. This result indicated that DNA high/hypermethylation is the main pathway for the regulation of ovarian cancer multidrug resistance compared with hypomethylation. However, there were a number of genes for which the methylation status and expression level were uncertain. Eyre et al (9) observed that ABCB1 (MDR1) gene expression presents hypomethylation in paclitaxel-resistant ovarian cancer cells and is involved in metastasis and resistance to chemotherapy in ovarian cancer through cancer stem cells and side population cells. However, there are also studies indicating that this gene has undergone DNA hypermethylation in drug-resistant ovarian cancer cells, and that its downregulation is involved in the development, progression and multidrug resistance of ovarian cancer by the c-Jun/JNK signalling pathway (10). Lee et al (11) observed that the downregulation of the MAL gene leads to tumourigenesis, while its upregulation increases the drug resistance of ovarian cancer.

DNA methylation is an essential mechanism for the regulation of the development of drug resistance in ovarian cancer, but the regulatory mechanism varies with different genes. The 26 methylated genes associated with ovarian cancer drug resistance in this study are involved in paclitaxel and cisplatin resistance of ovarian cancer through various mechanisms, including gene mismatch repair, gene microsatellite instability, cell repair defects, diminished DNA recognition capacity of cells, abnormal cell proliferation, apoptosis, cell growth, cell invasion and metastasis, prevention of intracellular drug accumulation, and associated signalling pathways (see Table I) (10-52). In all of the regulatory mechanisms, apoptosis may be a notable way for methylated genes to be involved in the regulation of ovarian cancer drug resistance since there are at least eight genes, including MLH1, PTEN and $\mathrm{ABCG} 2$, that participate in regulating ovarian cancer drug resistance through the cell apoptosis signalling pathway. In addition, five genes, including PTEN and BLU, are directly or indirectly involved in the regulation of the AKT signalling pathway, which has been reported to be critical in the regulation of apoptosis, cell proliferation, cell growth, metabolism and multidrug resistance (53). These results indicated that among the 26 methylated genes that are associated with the regulation of ovarian cancer drug resistance, at least half respond to ovarian cancer drug resistance by directly or indirectly involving an apoptosis signalling pathway.

Gene expression downregulation caused by DNA hypermethylation plays a notable role in the development of drug resistance in ovarian cancer. Therefore, therapies including the use of DNA methylation inhibitors to reverse the expression of DNA methylation may be a key trend for ovarian cancer treatment and for the mitigation of multidrug resistance. Studies have revealed that after adding the demethylation inhibitor 5-azacytidine or 5-aza-2 deoxycytidine to 11 genes, including MLH1, FBXO32 and TRAG-3, most of the sensitivity of ovarian cancer cells to chemotherapy drugs increased with varying degrees (see Table I). Hence, demethylation inhibitors have been increasingly used in clinical practice. However, certain genes, including BRCA1, PROM1, ABCG2, MAL, L1TD1 and FANCF, presented hypomethylation in ovarian cancer tissues, and the use of demethylation inhibitors may decrease ovarian cancer cell sensitivity to chemotherapy drugs or increase drug resistance (see Table I).

Biological processes enrichment. We conducted a biological process analysis on the 26 methylated genes that are associated with the regulation of ovarian cancer drug resistance (7). As shown in Table II, among the clusters of genes for the biological processes that have the highest score in enrichment, 


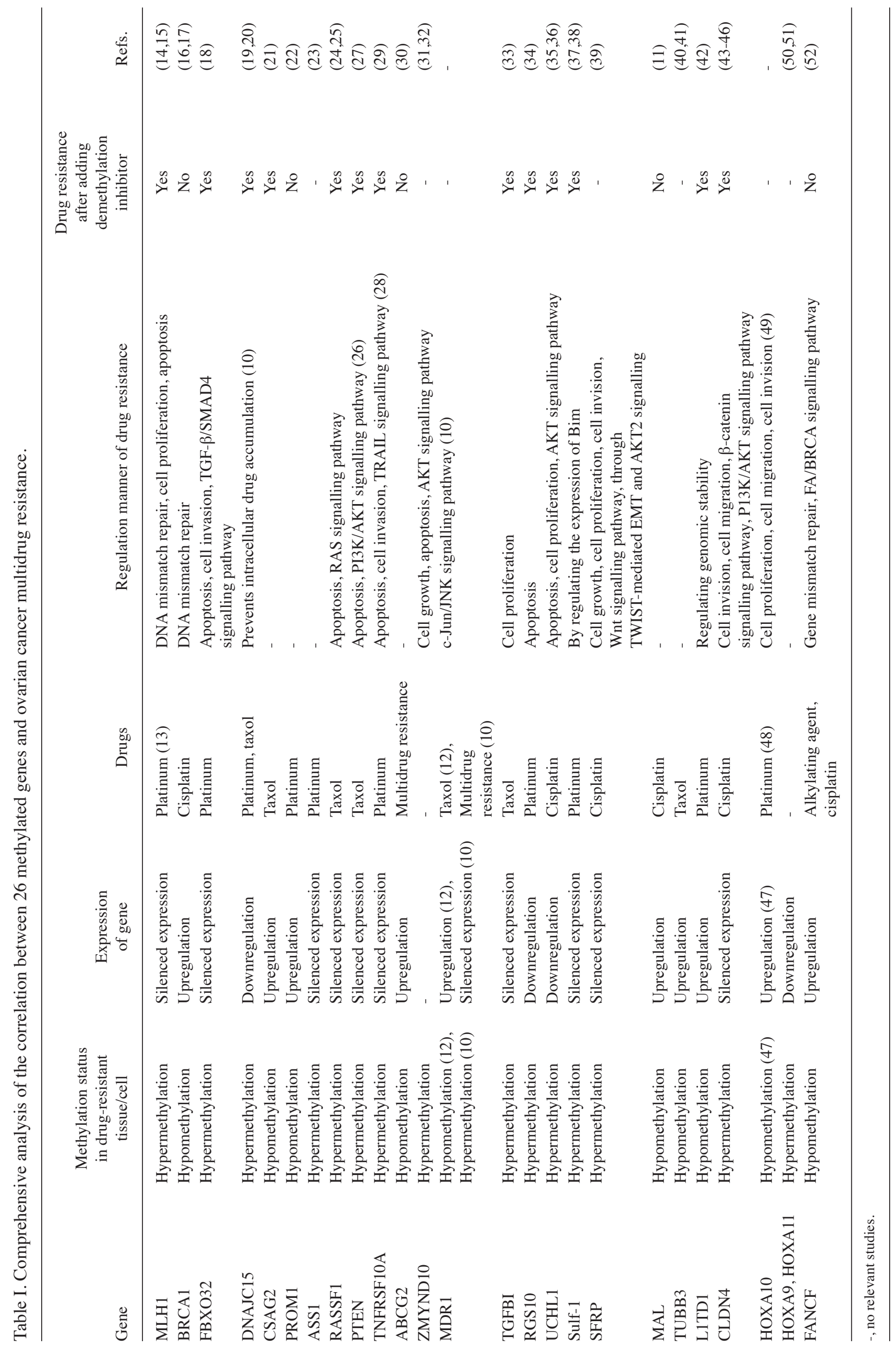


Table II. Results of biological process enrichment using DAVID.

\begin{tabular}{|c|c|c|}
\hline Enriched biological processes & Enriched genes & P-value \\
\hline \multirow{4}{*}{$\begin{array}{l}\text { Apoptosis-related } \\
\text { Induction of apoptosis } \\
\text { Positive regulation of apoptosis } \\
\text { Regulation of apoptosis }\end{array}$} & BRCA1, MAL, MLH1, PTEN, TNFRSF10, SFRP & \\
\hline & & 0.0016 \\
\hline & & 0.0047 \\
\hline & & 0.0083 \\
\hline \multirow{3}{*}{$\begin{array}{l}\text { Cell cycle-related } \\
\text { Microtubule-based process } \\
\text { Cell cycle }\end{array}$} & BRCA1, MLH1, TUBB3, UCHL1 & \\
\hline & & 0.0077 \\
\hline & & 0.0560 \\
\hline \multirow{2}{*}{$\begin{array}{l}\text { Drug-related } \\
\text { Response to drug }\end{array}$} & ABCB1, ABCG2, CSAG2, PTEN & \\
\hline & & 0.0490 \\
\hline \multicolumn{3}{|c|}{$\begin{array}{l}\text { Table III. Biological process annotation analysis of the interaction among } 20 \text { methylated genes and ovarian cancer (ovarian } \\
\text { neoplasms) and tumour drug resistance (drug resistance, neoplasms) using Coremine medical software. }\end{array}$} \\
\hline Input terms & Annotated biological process & P-value \\
\hline \multirow{11}{*}{$\begin{array}{l}20 \text { genes (MLH1, BRCA1, FBXO32, } \\
\text { DNAJC15, PROM1, RASSF1, PTEN, } \\
\text { TNFRSF10A, ABCG2, ZMYND10, } \\
\text { MDR1, TGFBI, UCHL1, SFRP, } \\
\text { TUBB3, CLDN4, HOXA10, HOXA9, } \\
\text { HOXA11, FANCF) AND ovarian neoplasms } \\
\text { AND drug resistance, neoplasms }\end{array}$} & DNA methylation & 0.00094 \\
\hline & Gene expression & 0.00133 \\
\hline & Methylation & 0.00133 \\
\hline & Apoptotic process & 0.00221 \\
\hline & Cell proliferation & 0.00361 \\
\hline & Cell cycle & 0.00562 \\
\hline & Signal transduction & 0.00594 \\
\hline & RNA interference & 0.00865 \\
\hline & Phosphorylation & 0.01780 \\
\hline & Cell death & 0.02020 \\
\hline & Pathogenesis & 0.02610 \\
\hline
\end{tabular}

cluster 1 consists of six genes primarily associated with apoptosis-related biological processes, and cluster 2 consists of four genes that are mainly related to cytoskeletal and cell cycle processes. These results suggest that DNA methylation is involved in the development of multidrug resistance in ovarian cancer mainly through apoptosis and cell cycle regulation. In addition, DAVID also enriched four methylated genes associated with drug response.

Protein interaction analysis for 26 methylated genes. To explain the correlation between all of the genes and ovarian cancer drug resistance, we conducted a comprehensive analysis of protein interactions for the 26 genes using the STRING (8) tool. As shown in Fig. 1, with the exception of the ASS1, MAL, CSAG2, Sulf-1, RGS10 and LITD1 genes/proteins, direct or indirect interactions were identified for the all genes. PTEN demonstrated a direct interaction with 13 genes, indicating that it may play a central role in these ovarian cancer drug resistance-related genes. PTEN has been proven to be a tumour suppressor gene, and it is involved in the cell cycle, cell division and apoptosis through negative regulation of the PTEN/P13K/AKT pathway $(53,54)$. Previous studies suggest that PTEN is also involved in drug resistance via the PI3K/AKT pathway. Reduction in PTEN expression was noted to result in the development of drug resistance in OVCAR-3 cells and the alterations conferred resistance to cisplatin through the activation of PI3K/AKT (55). Further research indicates that overexpression of PTEN reverses chemoresistance to cisplatin in human ovarian cancer cells through inactivation of the PI3K/AKT cell survival pathway (56). In addition to PTEN, ABCB1 and ABCG2 also have direct interactions with several other proteins in the network. It is indicated that these two genes may also play a key role in the ovarian cancer drug resistance regulated by DNA methylation. ABCB1 and ABCG2 are genes of the ABC transporter protein family and are associated with drug transport. The P-gp protein encoded by $\mathrm{ABCB} 1$ regulates the drug cumulative effect in tumour cells and eventually participates in the multidrug resistance process by being involved in drug transport across the membrane and in membrane stability maintenance (57); ABCG2 possesses ATP activity and is involved in biological processes, including drug transport and cell membrane stability (58). Chen et al (59) observed that $\mathrm{ABCB} 1$ and $\mathrm{ABCG} 2$ are involved in ovarian cancer drug resistance through the transcription factor Gli of the Hh signalling pathway. Gli expression inhibition may reduce $\mathrm{ABCB} 1$ and $\mathrm{ABCG} 2$ gene expression levels and strengthen the sensitivity of ovarian cancer to chemotherapy. The underlying mechanism is mainly the result of the joint action of Gli with its similar sequence in the ABCB1 and ABCG2 promoter regions. In addition, Hatle et al (10) observed that the reduced expression of DNAJC15 prevented the drug cumulative effect in cells by increasing the expression 


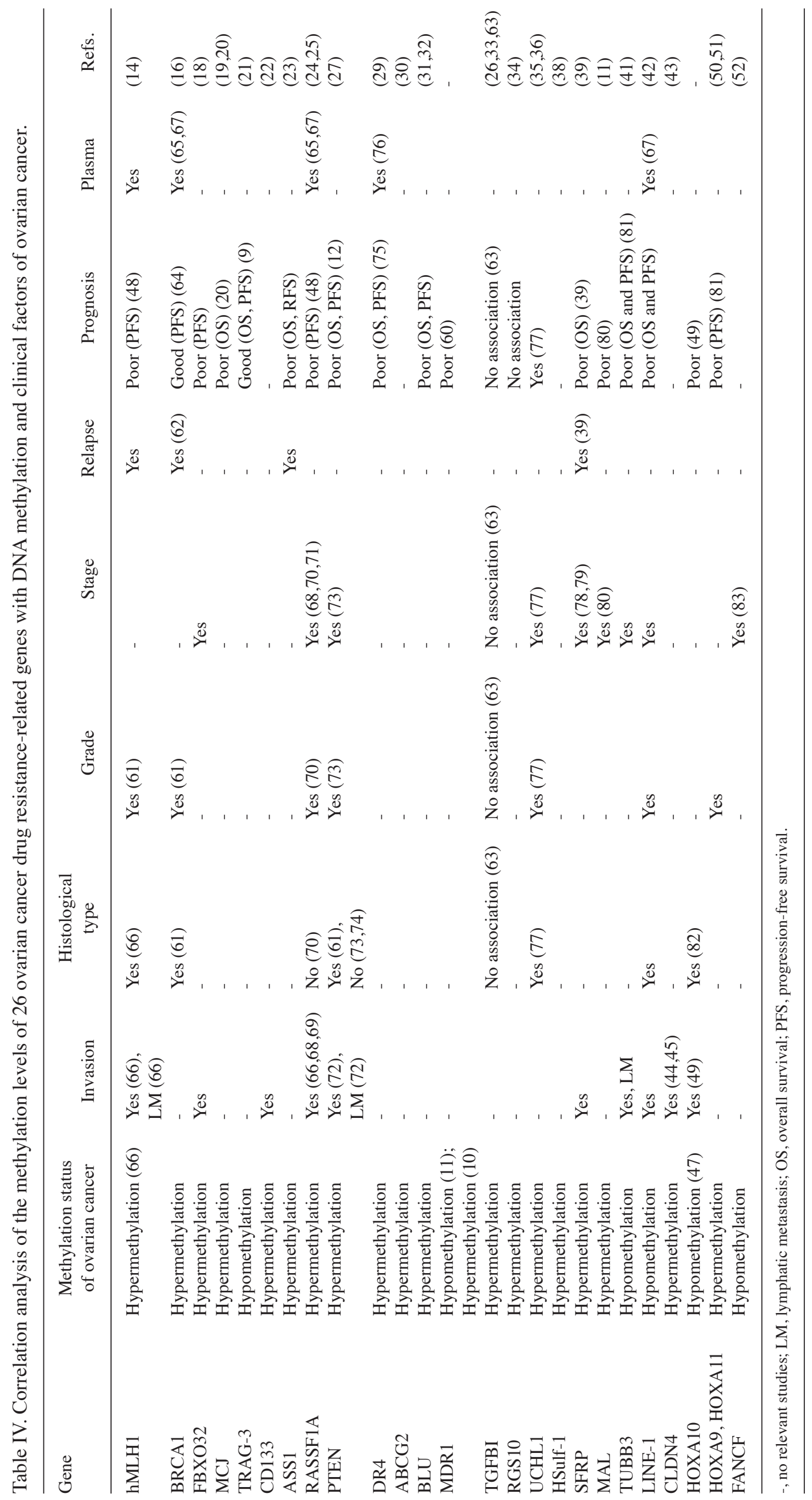




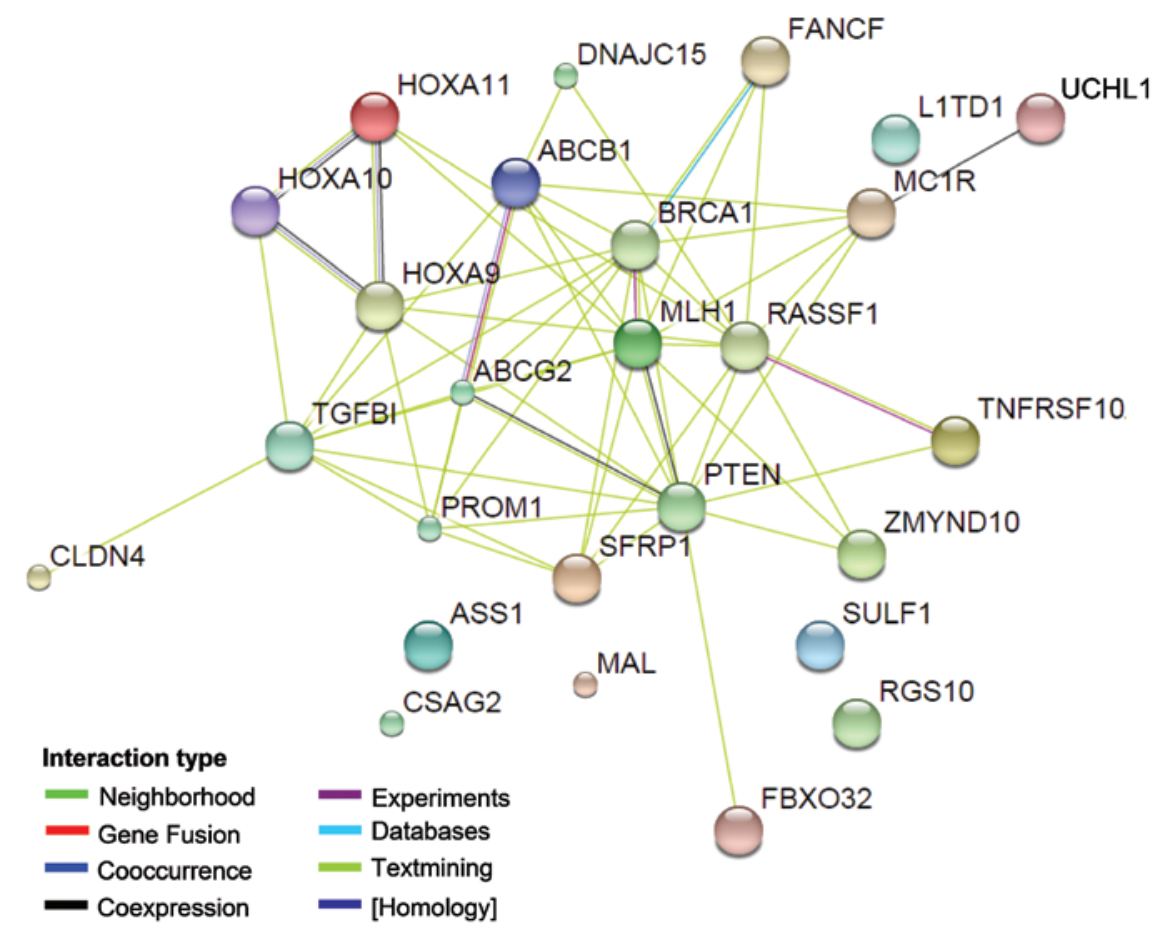

Figure 1. Unilateral interaction analysis of 26 ovarian cancer drug resistance-related genes with DNA methylation using STRING software. The line between two proteins represents the interaction between the two proteins. Different colours represent the different types of interactions, indicated by 'interaction type'.

of $\mathrm{ABCB} 1$, thus participating in the process of chemotherapy resistance in ovarian cancer.

As noted above, among the 26 methylated genes that are associated with ovarian cancer multidrug resistance, direct or indirect interactions were identified among 20 genes and their proteins (Fig. 1), indicating that these genes have significant correlations in their function. Therefore, to further analyse the for the regulation of ovarian cancer drug resistance by these 20 functionally correlated genes, we conducted an annotation analysis of the correlations among the genes (MLH1, BRCA1, FBXO32, DNAJC15, PROM1, RASSF1, PTEN, TNFRSF10A, ABCG2, ZMYND10, MDR1, TGFBI, UCHL1, SFRP, TUBB3, CLDN4, HOXA10, HOXA9, HOXA11 and FANCF) and ovarian cancer (ovarian neoplasms) and tumour resistance (drug resistance, neoplasms) using Coremine software (Fig. 1). As shown in Table III, a comprehensive analysis annotated 12 biological processes that were significantly correlated with the 20 genes, ovarian cancer and tumour drug resistance $(\mathrm{P}<0.05)$, indicating that the 20 genes may be involved in the regulation of ovarian cancer and multidrug resistance by acting on these 12 biological processes. Among the 12 annotated biological processes, DNA methylation had the highest score (DNA methylation, $\mathrm{P}=9.5 \mathrm{E}-4)$, fully illustrating a significant correlation between DNA methylation and these 20 genes, ovarian cancer and drug resistance. This result is consistent with the results summarised in Table I and they are considered to form a mutual basis for each other. Moreover, in addition to the biological processes of DNA methylation, the annotated biological processes also included apoptosis, cell proliferation, cell cycle and signal transduction.

Correlation analysis of ovarian cancer drug resistance-related methylated genes with malignant behaviour and prognosis. An integrated analysis of the correlation between the integrated 26 methylated genes and ovarian cancer malignant clinical behaviour and prognosis factors was also conducted. As shown in Table IV $(10,11,14,16,18-27,29-36,38,39,41-45,47-52,60-83)$, we observed that a considerable number of DNA methylated genes, including MLH1, FBXO32, PROM1, RASSF1, PTEN, SFRP, TUBB3, L1TD1 and CLDN4, were associated with the invasion of ovarian cancer. Each gene was hypermethylated, resulting in the silencing of gene expression in ovarian cancer and drug-resistant tissue or cells and ultimately regulating tumour invasion. MLH1, FBXO32 and TUBB3 are associated with ovarian cancer lymph node metastasis, while HOXA10 hypomethylation is associated with ovarian cancer metastasis behaviour (50). In addition, a number of the 26 methylated genes revealed a significant correlation with the type, pathological grade and clinical stage of ovarian cancer. For example, methylation changes in MLH1, BRCA1, PTEN, UCHL1, L1TD1 and HOXA10 were associated with the histological type and pathological grade. Studies have revealed that MLH1 methylation changes are related to serous pathologically well-differentiated ovarian cancer, with statistical significance, while methylation changes in PTEN are related to mucinous ovarian cancer, with statistical significance (61). In addition, the methylation of nine genes (FBXO32, RASSF1, PTEN, UCHL1, SFRP, MAL, TUBB3, L1TD1 and FANCF) was correlated with the clinical stage of ovarian cancer, and the DNA methylation of four genes [MLH1 (14), BRCA1 (62), ASS1 (23) and SFRP (39)] was correlated with recurrence (Table IV).

DNA methylated genes associated with drug resistance regulation have a significant correlation with ovarian cancer prognosis (Table IV). Among the 26 methylated genes, the methylation of ABCG2, Sulf-1, FANCF, CLDN4, TGFBI (63) 
and RGS10 (34) has been reported not to be associated with the prognosis of ovarian cancer. However, the methylation or abnormal expression of the remaining 20 genes are all statistically relevant to ovarian cancer prognosis. As shown in Table IV, most gene methylation and the subsequent expression changes are relevant to the poor prognosis of ovarian cancer, shortening overall survival (OS) and progression-free survival (PFS), while methylation changes in the BRCA1 and CSAG2 genes are correlated with longer PFS and OS (84,64). In addition, studies have indicated that the methylation of SOX1 and LMX1A is related to a patient's long-term survival rate (85). Given that ovarian cancer drug resistance-related methylated genes are significantly related to ovarian cancer prognosis, the joint detection of the DNA methylation levels in plasma may be an significant approach for ovarian carcinoma clinical prediction and prognostic analysis. In fact, there have been studies demonstrating that plasma DNA methylation may be a biomarker for the early diagnosis of ovarian cancer. As shown in Table IV, the methylation status and levels of MLH1, BRCA1, RASSF1, TNFRSF10A and L1TD1 were significantly changed in the plasma of patients with early ovarian cancer. Further studies have revealed that in the plasma DNA in 50 ovarian cancer patients, at least one promoter of BRCAl and RASSF1 was in a state of hypermethylation in $68 \%$ of the patients. Methylation testing combining these two genes with four other genes (APC, DAPK, p14ARF and p16INK4a) increases the diagnosis susceptibility of ovarian cancer to $100 \%$. The methylation of all six genes was negative in the plasma DNA of the peripheral blood of 20 normal females; i.e., the diagnostic specificity was $100 \%$ (65). Thus, DNA methylation status detection, particularly DNA methylation status detection in plasma, has broad application prospects for the diagnosis of ovarian cancer.

\section{Discussion}

Ovarian cancer is a gynaecological cancer with a high mortality rate. The main reason for chemotherapy failure is the development of multidrug resistance. DNA methylation is an epigenetic mechanism that plays a crucial role in the development, progression and drug resistance of ovarian cancer. To date, there has been extensive research into the correlation between ovarian cancer drug resistance and DNA methylation, and notable relevant research results have been reported. However, most of the current studies in this area are focused on DNA methylation level assays in ovarian cancer tissue or cells, or on the regulation of the development and drug resistance in ovarian cancer by methylation of one or several genes. Research is relatively dispersed, and there are few studies concerning the comprehensive analysis of gene methylation mechanisms related to ovarian cancer drug resistance and their association with clinical factors. In the present study, we conducted an integrated analysis of the correlation between the 26 methylated genes and ovarian cancer, multidrug resistance and a number of other clinical factors. Focusing on the effects of these genes on the drug resistance mechanisms, prognosis and malignant behaviour of ovarian carcinoma, this study provides guidance on the choice of chemotherapy drugs used in clinical settings, early detection and prognosis. At the same time, we carried out bioinformatics analyses, including biological process annotation and protein-protein interaction, providing evidence for integrated research of DNA methylation genes that play a role in ovarian cancer and drug resistance.

Through DAVID bioprocess enrichment analysis, we observed that the 26 ovarian cancer-related methylated genes were significantly correlated with apoptosis (see Table IV); Coremine medical analysis of the 20 methylated genes that have the closest interaction among each other (Fig. 1) demonstrated that apoptosis is one of the biological processes that is significantly correlated with these 20 genes, ovarian cancer and drug resistance (Table III). These results indicate that DNA methylation involves the regulation of multidrug resistance in ovarian cancer through apoptosis. The latter finding is in good agreement with that of previous studies $(86,87)$. As shown in Table I, there are at least seven genes, including PTEN, BLU and UCHL1, that participate in the regulation of multidrug resistance in ovarian cancer through cell apoptosis. Apoptosis is autonomous programmed cell death for the maintenance of homeostasis. Unlike necrosis, apoptosis is not a passive process but an active process that involves a series of functions, including gene activation, expression and regulation. Apoptosis is not self-injury under pathological conditions but an initiative death process to better adapt to the living environment (88). Studies have revealed that a number of genes are involved in the regulation of ovarian cancer multidrug resistance through apoptosis. For example, the reduction of the expression of the tumour suppressor gene PTEN was accompanied by increased expression of $\mathrm{Bcl}-2$, which is widely recognised as an anti-apoptotic gene. The presence of Bcl-2 helps to maintain normal cell proliferation and prevents cisplatin-mediated apoptosis by blocking the release of cytochrome $c$ from mitochondria, thereby participating in the regulation of ovarian cancer cisplatin resistance (89). Similarly, the tumour suppressor gene BLU acts through the downregulation of Bcl-2 and the upregulation of Bax, P21 and $\mathrm{P} 53$, causing apoptosis and responding to paclitaxel resistance in ovarian cancer (31). Another example is that UCHL1 promotes sensitivity to cisplatin in ovarian cancer cells by promoting apoptosis (36). In summary, these results demonstrate that apoptosis may be an essential mechanism by which methylated genes regulate drug resistance in ovarian cancer. In-depth research of the role of methylated genes in the regulation of apoptosis in ovarian cancer is likely to provide further opportunities to overcome multidrug resistance.

Platinum- and paclitaxel-based drugs are currently the main chemotherapy drugs used in the clinical treatment of ovarian cancer. Based on our overall analysis (Table I), gene methylation is the primary reason for resistance to these types of drugs in ovarian cancer cells. Thus, the reversal of gene methylation status may be the key to overcoming resistance to platinum or paclitaxel. It has been proven that the reversal of the methylation status of certain genes effectively reverses the resistance to chemotherapeutic drugs in ovarian cancer cells. Strathdee et al (90) demonstrated that the methylation level of the hMLHl gene in cisplatin-resistant A2780 cells was significantly higher than that in cisplatin-sensitive cells. Following treatment with the DNA methylation inhibitor 5-azacytidine, A2780 drug-resistant cells restored the sensitivity to cisplatin, while the DNA methylation levels in hMLHl were also significantly decreased, indicating that increased sensitivity to the drug in ovarian cancer is, at least in part, due to the decreased DNA methylation level in 
the hMLHl gene. Additionally, Kassler et al (25) noted that the hypermethylation status in the RASSF1A gene promoter in paclitaxel-resistant ovarian cancer cells and the forced increase of RASSF1A gene expression enhanced the sensitivity of ovarian cancer to paclitaxel. This result indicates that the expression silencing caused by RASSF1A methylation causes paclitaxel resistance of ovarian cancer cells and that the stimulation of the demethylation status by forcing the re-expression of RASSF1A effectively increases the sensitivity of the cells to the drugs. These results indicate that the demethylation of methylated genes reverses drug resistance in ovarian cancer cells to some extent. Therefore, demethylating drugs have been increasingly used in clinical settings. For example, DNMT inhibitors, including 5-azacytidine and its deoxyribose analogues (5-azacytidine) or 5-aza-2 deoxycytidine, decitabine and other demethylating drugs, have been used in cancer chemotherapy. In summary, the comprehensive analysis and detection of ovarian cancer drug resistance-related methylated genes may guide clinical drug choice to a certain extent, providing significant clinical value.

This study also performed an integrated analysis of the correlation between ovarian cancer drug resistance-related methylated genes and ovarian cancer malignant behaviour. Overall, there are relatively few studies concerning ovarian cancer drug resistance-related methylated genes and ovarian cancer malignant behaviour. As shown in Table II, among all 26 genes, 9 genes (including PTEN) are related to ovarian cancer staging, 7 genes (including MLH1) are related to ovarian cancer invasion, 6 genes (including BRCA1) are related to the histological type of ovarian cancer, and 6 genes (including RASSF1A) are related to ovarian cancer grading. However, the correlation between the remaining methylated genes and ovarian cancer malignant behaviour is unclear. Furthermore, methylation status changes in drug resistance-related methylated genes in ovarian cancer were significantly associated with the prognosis of ovarian cancer. As shown in Table IV, 19 of the 26 methylated genes, including hMLH1, are associated with ovarian cancer prognosis, of which hypermethylation of at least 13 genes, including ASS1, is significantly associated with poor prognosis. The latter findings were mainly characterised by a significant shortening of OS and PFS. These results suggest that the methylation level of ovarian cancer resistance-related genes is a good prognostic marker and that an integrated analysis of multiple methylated genes may better predict the prognosis.

\section{Conclusion}

An integrated analysis of the correlation between 26 methylated genes and drug resistance in ovarian cancer and a relevant bioinformatics analysis were conducted in this study. Protein/gene interactions revealed that at least 20 of the 26 genes interact with each other (Fig. 1) and that PTEN, $\mathrm{ABCB} 1$ and $\mathrm{ABCG} 2$ have direct interaction with most of the other genes in the network. This result suggests that overall, these methylated genes may participate in the regulation of ovarian cancer drug resistance and that genes including PTEN may be key regulators. Annotations on biological processes using DAVID and Coremine (Tables II and III) indicated that apoptosis may be a significant mechanism of drug resistance by methylated genes. In addition, the integrated analysis revealed that re-expression caused by demethylation reverses tolerance to chemotherapeutic drugs in ovarian cancer to a certain extent. This observation indicates that the application prospect of demethylating drugs in clinical practice may be broader than previously considered. In addition, this study demonstrated that the methylation levels of ovarian cancer drug-resistant methylated genes were significantly associated with poor prognosis in ovarian cancer (Table IV). In summary, this study explains the potential correlation between methylated genes and drug resistance in ovarian cancer with the potential to guide our understanding of the regulation of ovarian cancer drug resistance by gene methylation, treatment and improvement of the prognosis of ovarian cancer.

\section{Acknowledgements}

The study was supported by the Natural Science Foundation of Guangxi (grant no. 2014jjAA40637) and the Key Health Science Foundation of Guangxi (grant no. 14124004-1-24).

\section{References}

1. Cho KR and Shih IeM: Ovarian cancer. Annu Rev Pathol 4: 287-313, 2009.

2. Balch C, Huang TH, Brown R and Nephew KP: The epigenetics of ovarian cancer drug resistance and resensitization. Am J Obstet Gynecol 191: 1552-1572, 2004.

3. Novik KL, Nimmrich I, Genc B, Maier S, Piepenbrock C, Olek A and Beck S: Epigenomics: genome-wide study of methylation phenomena. Curr Issues Mol Biol 4: 111-28, 2002.

4. Lund AH and van Lohuizen M: Epigenetics and cancer. Genes Dev 18: 2315-2335, 2004.

5. Seeber LM and van Diest PJ: Epigenetics in ovarian cancer. Methods Mol Biol 863: 253-69, 2012.

6. Widschwendter M, Jiang G, Woods C, Müller HM, Fiegl H, Goebel G, Marth C, Müller-Holzner E, Zeimet AG, Laird PW and Ehrlich M: DNA hypomethylation and ovarian cancer biology. Cancer Res 64: 4472-4480, 2004.

7. Zhang B, Kirov S and Snoddy J: WebGestalt: an integrated system for exploring gene sets in various biological contexts. Nucleic Acids Res 33 (Web Server issue): W741-W748, 2005.

8. Franceschini A, Szklarczyk D, Frankild S, Kuhn M, Simonovic M, Roth A, Lin J, Minguez P, Bork P, von Mering C and Jensen LJ: STRING v9.1: Protein-protein interaction networks, with increased coverage and integration. Nucleic Acids Res 41 (Database issue): D808-D815, 2013.

9. Eyre R, Harvey I, Stemke-Hale K, Lennard TW, Tyson-Capper A and Meeson AP: Reversing paclitaxel resistance in ovarian cancer cells via inhibition of the ABCB1 expressing side population. Tumour Biol 35: 9879-9892, 2014.

10. Hatle KM, Neveu W, Dienz O, Rymarchyk S, Barrantes R, Hale S, Farley N, Lounsbury KM, Bond JP, Taatjes D and Rincón M: Methylation-controlled J protein promotes c-Jun degradation to prevent ABCB1 transporter expression. Mol Cell Biol 27: 2952-66, 2007.

11. Lee PS, Teaberry VS, Bland AE, et al: Elevated MAL expression is accompanied by promoter hypomethylation and platinum resistance in epithelial ovarian cancer. Int J Cancer 126: 1378-1389, 2010.

12. Harvey I, Stemke-Hale K, Lennard TW, Tyson-Capper A and Meeson AP: Reversing paclitaxel resistance in ovarian cancer cells via inhibition of the ABCB1 expressing side population. Tumour Biol 35: 9879-9892, 2014.

13. Watanabe Y, Ueda H, Etoh T, Koike E, Fujinami N, Mitsuhashi A and Hoshiai $\mathrm{H}$ : A change in promoter methylation of hMLH1 is a cause of acquired resistance to platinum-based chemotherapy in epithelial ovarian cancer. Anticancer Res 27: 1449-1452, 2007.

14. Gifford G, Paul J, Vasey PA, Kaye SB and Brown R: The acquisition of hMLH1 methylation in plasma DNA after chemotherapy predicts poor survival for ovarian cancer patients. Clin Cancer Res 10: 4420-4426, 2004. 
15. Calin GA, Sevignani C, Dumitru CD, Hyslop T, Noch E, Yendamuri S, Shimizu M, Rattan S, Bullrich F, Negrini M and Croce CM: Human microRNA genes are frequently located at fragile sites and genomic regions involved in cancers. Proc Natl Acad Sci USA 101: 2999-3004, 2004.

16. Stordal B, Timms K, Farrelly A, Gallagher D, Busschots S, Renaud M, Thery J, Williams D, Potter J, Tran T, et al: BRCA1/2 mutation analysis in 41 ovarian cell lines reveals only one functionally deleterious BRCA1 mutation. Mol Oncol 7: 567-579, 2013.

17. Wang YQ, Zhang JR, Li SD, He YY, Yang YX, Liu XL and Wan XP: Aberrant methylation of breast and ovarian cancer susceptibility gene 1 in chemosensitive human ovarian cancer cells does not involve the phosphatidylinositol 3'-kinase-Akt pathway. Cancer Sci 101: 1618-1623, 2010.

18. Chou JL, Su HY, Chen LY, Liao YP, Hartman-Frey C, Lai YH, Yang HW, Deatherage DE, Kuo CT, Huang YW, et al: Promoter hypermethylation of FBXO32, a novel TGF-beta/SMAD4 target gene and tumor suppressor, is associated with poor prognosis in human ovarian cancer. Lab Invest 90: 414-25, 2010.

19. Strathdee G, Vass JK, Oien KA, Siddiqui N, Curto-Garcia J and Brown R: Demethylation of the MCJ gene in stage III/IV epithelial ovarian cancer and response to chemotherapy. Gynecol Oncol 97: 898-903, 2005

20. Strathdee G, Davies BR, Vass JK, Siddiqui N and Brown R: Cell type-specific methylation of an intronic $\mathrm{CpG}$ island controls expression of the MCJ gene. Carcinogenesis 25: 693-701, 2004.

21. Yao X, Hu JF, Li T, Yang Y, Sun Z, Ulaner GA, Vu TH and Hoffman AR: Epigenetic regulation of the taxol resistance-associated gene TRAG-3 in human tumors. Cancer Genet Cytogenet 151: 1-13, 2004.

22. Baba T, Convery PA, Matsumura N, Whitaker RS, Kondoh E, Perry T, Huang Z, Bentley RC, Mori S, Fujii S, et al: Epigenetic regulation of CD133 and tumorigenicity of CD133+ ovarian cancer cells. Oncogene 28: 209-218, 2009.

23. Nicholson LJ, Smith PR, Hiller L, Szlosarek PW, Kimberley C, Sehouli J, Koensgen D, Mustea A, Schmid P and Crook T: Epigenetic silencing of argininosuccinate synthetase confers resistance to platinum-induced cell death but collateral sensitivity to arginine auxotrophy in ovarian cancer. Int J Cancer 125 : $1454-1463,2009$.

24. Vos MD, Martinez A, Elam C, Dallol A, Taylor BJ, Latif F and Clark GJ: A role for the RASSF1A tumor suppressor in the regulation of tubulin polymerization and genomic stability. Cancer Res 64: 4244-4250, 2004.

25. Kassler S, Donninger H, Birrer MJ and Clark GJ: RASSF1A and the Taxol response in ovarian cancer. Mol Biol Int 2012: 263267, 2012.

26. Blanco-Aparicio C, Renner O, Leal JF and Carnero A: PTEN, more than the AKT pathway. Carcinogenesis 28: 1379-1386, 2007.

27. Dai F, Zhang Y, Zhu X, Shan N and Chen Y: Anticancer role of MUC1 aptamer-miR-29b chimera in epithelial ovarian carcinoma cells through regulation of PTEN methylation. Target Oncol 7: 217-225, 2012

28. Horak P, Pils D, Haller G, Pribill I, Roessler M, Tomek S, Horvat R, Zeillinger R, Zielinski C and Krainer M: Contribution of epigenetic silencing of tumor necrosis factor-related apoptosis inducing ligand receptor 1 (DR4) to TRAIL resistance and ovarian cancer. Mol Cancer Res 3: 335-343, 2005.

29. Li Y, Hu W, Shen DY, Kavanagh JJ and Fu S: Azacitidine enhances sensitivity of platinum-resistant ovarian cancer cells to carboplatin through induction of apoptosis. Am J Obstet Gynecol 200: 177 e1-e9, 2009.

30. Bram EE, Hu W, Shen DY, Kavanagh JJ and Fu S: Chemotherapeutic drug-induced ABCG2 promoter demethylation as a nove mechanism of acquired multidrug resistance. Neoplasia 11 1359-1370, 2009.

31. Park ST, Byun HJ, Kim BR, Dong SM, Park SH, Jang PR and Rho S: Tumor suppressor BLU promotes paclitaxel antitumor activity by inducing apoptosis through the down-regulation of Bcl-2 expression in tumorigenesis. Biochem Biophys Res Commun 435: 153-159, 2013.

32. Chiang YC, Chang MC, Chen PJ, Wu MM, Hsieh CY, Cheng WF and Chen CA: Epigenetic silencing of BLU through interfering apoptosis results in chemoresistance and poor prognosis of ovarian serous carcinoma patients. Endocr Relat Cancer 20 213-227, 2013

33. Wang N, Zhang H, Yao Q, Wang Y, Dai S and Yang X: TGFBI promoter hypermethylation correlating with paclitaxel chemoresistance in ovarian cancer. J Exp Clin Cancer Res 31: 6, 2012.
34. Ali MW, Cacan E, Liu Y, Pierce JY, Creasman WT, Murph MM, Govindarajan R, Eblen ST, Greer SF and Hooks SB: Transcriptional suppression, DNA methylation and histone deacetylation of the regulator of G-protein signaling 10 (RGS10) gene in ovarian cancer cells. PLoS One 8: e60185, 2013.

35. Okochi-Takada E, Nakazawa K, Wakabayashi M, Mori A, Ichimura S, Yasugi T and Ushijima T: Silencing of the UCHL1 gene in human colorectal and ovarian cancers. Int J Cancer 119 1338-1344, 2006

36. Jin C, Yu W, Lou X, Zhou F, Han X, Zhao N and Lin B: UCHL1 is a putative tumor suppressor in ovarian cancer cells and contributes to cisplatin resistance. J Cancer 4: 662-670, 2013.

37. He X, Khurana A, Roy D, Kaufmann S and Shridhar V: Loss of HSulf-1 expression enhances tumorigenicity by inhibiting Bim expression in ovarian cancer. Int J Cancer 135: 1783-1789, 2014.

38. Lai J, Chien J, Staub J, Avula R, Greene EL, Matthews TA, Smith DI, Kaufmann SH, Roberts LR and Shridhar V: Loss of HSulf-1 up-regulates heparin-binding growth factor signaling in cancer. J Biol Chem 278: 23107-23117, 2003.

39. Su HY, Lai HC, Lin YW, Liu CY, Chen CK, Chou YC, Lin SP, Lin WC, Lee HY and Yu MH: Epigenetic silencing of SFRP5 is related to malignant phenotype and chemoresistance of ovarian cancer through Wnt signaling pathway. Int J Cancer 127: 555-567, 2010.

40. Gao S, Zhao X, Lin B, Hu Z, Yan L and Gao J: Clinical implications of REST and TUBB3 in ovarian cancer and its relationship to paclitaxel resistance. Tumour Biol 33: 1759-1765, 2012.

41. Izutsu N, Maesawa C, Shibazaki M, Oikawa H, Shoji T, Sugiyama $\mathrm{T}$ and Masuda T: Epigenetic modification is involved in aberrant expression of class III beta-tubulin, TUBB3, in ovarian cancer cells. Int J Oncol 32: 1227-1235, 2008.

42. Pattamadilok J, Huapai N, Rattanatanyong P, Vasurattana A, Triratanachat S, Tresukosol D and Mutirangura A: LINE-1 hypomethylation level as a potential prognostic factor for epithelial ovarian cancer. Int J Gynecol Cancer 18: 711-717, 2008.

43. Litkouhi B, Kwong J, Lo CM, Smedley JG III, McClane BA, Aponte M, Gao Z, Sarno JL, Hinners J, Welch WR, et al: Claudin-4 overexpression in epithelial ovarian cancer is associated with hypomethylation and is a potential target for modulation of tight junction barrier function using a C-terminal fragment of Clostridium perfringens enterotoxin. Neoplasia 9: 304-314, 2007.

44. Lin X, Shang X, Manorek G and Howell SB: Regulation of the Epithelial-Mesenchymal Transition by Claudin-3 and Claudin- 4 . PLoS One 8: e67496, 2013

45. Shang X, Lin X, Alvarez E, Manorek G and Howell SB: Tight junction proteins claudin-3 and claudin-4 control tumor growth and metastases. Neoplasia 14: 974-985, 2012

46. Shang X, Lin X, Manorek G and Howell SB: Claudin-3 and claudin-4 regulate sensitivity to cisplatin by controlling expression of the copper and cisplatin influx transporter CTR1. Mol Pharmacol 83: 85-94, 2013.

47. Jiang Y, Chu Y, Tang W, Wan Y, Zhang L and Cheng W: Transcription factor WT1 and promoter CpG hypomethylation coactivate HOXA10 expression in ovarian cancer. Curr Pharm Des 20: 1647-1654, 2014.

48. Matei D, Fang F, Shen C, Schilder J, Arnold A, Zeng Y, Berry WA, Huang T and Nephew KP: Epigenetic resensitization to platinum in ovarian cancer. Cancer Res 72: 2197-2205, 2012.

49. Li B, Jin H, Yu Y, Gu C, Zhou X, Zhao N and Feng Y: HOXA10 is overexpressed in human ovarian clear cell adenocarcinoma and correlates with poor survival. Int J Gynecol Cancer 19: 1347-1352, 2009

50. Widschwendter M, Apostolidou S, Jones AA, Fourkala EO, Arora R, Pearce CL, Frasco MA, Ayhan A, Zikan M, Cibula D, et al: HOXA methylation in normal endometrium from premenopausal women is associated with the presence of ovarian cancer: a proof of principle study. Int J Cancer 125: 2214-2218, 2009

51. Fiegl H, Windbichler G, Mueller-Holzner E, Goebel G, Lechner M, Jacobs IJ and Widschwendter M: HOXA11 DNA methylation - a novel prognostic biomarker in ovarian cancer. Int J Cancer 123: 725-729, 2008

52. Taniguchi T, Tischkowitz M, Ameziane N, Hodgson SV, Mathew CG, Joenje H, Mok SC and D'Andrea AD: Disruption of the Fanconi anemia-BRCA pathway in cisplatin-sensitive ovarian tumors. Nat Med 9: 568-574, 2003.

53. Cai J, Xu L, Tang H, Yang Q, Yi X, Fang Y, Zhu Y and Wang Z: The role of the PTEN/PI3K/Akt pathway on prognosis in epithelial ovarian cancer: a meta-analysis. Oncologist 19: $528-535,2014$ 
54. Chu EC and Tarnawski AS: PTEN regulatory functions in tumor suppression and cell biology. Med Sci Monit 10: RA235-RA241, 2004.

55. Lee S, Choi EJ, Jin C and Kim DH: Activation of PI3K/Akt pathway by PTEN reduction and PIK3CA mRNA amplification contributes to cisplatin resistance in an ovarian cancer cell line. Gynecol Oncol 97: 26-34, 2005.

56. Wu H, Cao Y, Weng D, Xing H, Song X, Zhou J, Xu G, Lu Y, Wang S and Ma D: Effect of tumor suppressor gene PTEN on the resistance to cisplatin in human ovarian cancer cell lines and related mechanisms. Cancer Lett 271: 260-271, 2008.

57. Sui H, Fan ZZ and Li Q: Signal transduction pathways and transcriptional mechanisms of ABCB1/Pgp-mediated multiple drug resistance in human cancer cells. J Int Med Res 40: 426-435, 2012.

58. Krishnamurthy $P$ and Schuetz JD: Role of ABCG2/BCRP in biology and medicine. Annu Rev Pharmacol Toxicol 46: 381-410, 2006

59. Chen Y, Bieber MM and Teng NN: Hedgehog signaling regulates drug sensitivity by targeting $\mathrm{ABC}$ transporters $\mathrm{ABCB} 1$ and ABCG2 in epithelial ovarian cancer. Mol Carcinog 53: 625-634, 2014.

60. Schneider J, Jimenez E, Marenbach K, Marx D and Meden H: Co-expression of the MDR1 gene and HSP27 in human ovarian cancer. Anticancer Res 18: 2967-2971, 1998.

61. Yang HJ, Liu VW, Wang Y, Tsang PC and Ngan HY: Differential DNA methylation profiles in gynecological cancers and correlation with clinico-pathological data. BMC Cancer 6: 212, 2006.

62. Swisher EM, Gonzalez RM, Taniguchi T, Garcia RL, Walsh T, Goff BA and Welcsh P: Methylation and protein expression of DNA repair genes: association with chemotherapy exposure and survival in sporadic ovarian and peritoneal carcinomas. Mol Cancer 8: 48, 2009.

63. Kang S, Dong SM and Park NH: Frequent promoter hypermethylation of TGFBI in epithelial ovarian cancer. Gynecol Oncol 118: 58-63, 2010

64. Ignatov T, Eggemann H, Costa SD, Roessner A, Kalinski T and Ignatov A: BRCA1 promoter methylation is a marker of better response to platinum-taxane-based therapy in sporadic epithelia ovarian cancer. J Cancer Res Clin Oncol 140: 1457-1463, 2014

65. Ibanez de Caceres I, Battagli C, Esteller M, Herman JG Dulaimi E, Edelson MI, Bergman C, Ehya H, Eisenberg BL and Cairns P: Tumor cell-specific BRCA1 and RASSF1A hypermethylation in serum, plasma and peritoneal fluid from ovarian cancer patients. Cancer Res 64: 6476-6481, 2004.

66. Zhang H, Zhang S, Cui J, Zhang A, Shen L and Yu H: Expression and promoter methylation status of mismatch repair gene hMLH1 and hMSH2 in epithelial ovarian cancer. Aust N Z J Obstet Gynaecol 48: 505-509, 2008.

67. Fang F, Balch C, Schilder J, Breen T, Zhang S, Shen C, Li L, Kulesavage C, Snyder AJ, Nephew KP and Matei DE: A phase 1 and pharmacodynamic study of decitabine in combination with carboplatin in patients with recurrent, platinum-resistant, epithelial ovarian cancer. Cancer 116: 4043-4053, 2010.

68. Bhagat R, Chadaga S, Premalata CS, Ramesh G, Ramesh C, Pallavi VR and Krishnamoorthy L: Aberrant promoter methylation of the RASSF1A and APC genes in epithelial ovarian carcinoma development. Cell Oncol (Dordr) 35: 473-479, 2012.

69. Bondurant AE, Huang Z, Whitaker RS, Simel LR, Berchuck A and Murphy SK: Quantitative detection of RASSF1A DNA promoter methylation in tumors and serum of patients with serous epithelial ovarian cancer. Gynecol Oncol 123: 581-587, 2011.

70. Ma L, Zhang JH, Liu FR and Zhang X: Hypermethylation of promoter region of RASSF1A gene in ovarian malignant epithelial tumors. Zhonghua Zhong Liu Za Zhi 27: 657-659, 2005 (In Chinese)

71. Liggett TE, Melnikov A, Yi Q, Replogle C, Hu W, Rotmensch J, Kamat A, Sood AK and Levenson V: Distinctive DNA methylation patterns of cell-free plasma DNA in women with malignant ovarian tumors. Gynecol Oncol 120: 113-120, 2011.

72. Shen Y, Shen R, Ge L, Zhu Q and Li F: Fibrillar type I collagen matrices enhance metastasis/invasion of ovarian epithelial cancer via $\beta 1$ integrin and PTEN signals. Int J Gynecol Cancer 22: $1316-1324,2012$.
73. Qiao YH, Cheng J and Guo RX: Expression of phosphorylated protein kinase B and PTEN protein in ovarian epithelial cancer. Zhonghua Fu Chan Ke Za Zhi 42: 325-329, 2007 (In Chinese).

74. Che Y, Yao Q, Dai S, Luo B and Wang Y: Study of the mutation and expression of PTEN gene in endometrial carcinoma and epithelial ovarian cancer. Zhonghua Fu Chan Ke Za Zhi 37: 608-611, 2002 (In Chinese).

75. Dong HP, Kleinberg L, Silins I, Flørenes VA, Tropé CG, Risberg B, Nesland JM and Davidson B: Death receptor expression is associated with poor response to chemotherapy and shorter survival in metastatic ovarian carcinoma. Cancer 112: 84-93, 2008.

76. Fu S, Hu W, Iyer R, Kavanagh JJ, Coleman RL, Levenback CF, Sood AK, Wolf JK, Gershenson DM, Markman M, et al: Phase $1 \mathrm{~b}-2 \mathrm{a}$ study to reverse platinum resistance through use of a hypomethylating agent, azacitidine, in patients with platinum-resistant or platinum-refractory epithelial ovarian cancer. Cancer 117: 1661-1669, 2011.

77. Brait M, Maldonado L, Noordhuis MG, Begum S, Loyo M, Poeta ML, Barbosa A, Fazio VM, Angioli R, Rabitti C, et al: Association of promoter methylation of VGF and PGP9.5 with ovarian cancer progression. PLoS One 8: e70878, 2013.

78. Al-Shabanah OA, Hafez MM, Hassan ZK, Sayed-Ahmed MM, Abozeed WN, Alsheikh A and Al-Rejaie SS: Methylation of SFRPs and APC genes in ovarian cancer infected with high risk human papillomavirus. Asian Pac J Cancer Prev 15: 2719-2725, 2014.

79. Saran U, Arfuso F, Zeps N and Dharmarajan A: Secreted frizzled-related protein 4 expression is positively associated with responsiveness to cisplatin of ovarian cancer cell lines in vitro and with lower tumour grade in mucinous ovarian cancers. BMC Cell Biol 13: 25, 2012.

80. Berchuck A, Iversen ES, Luo J, Clarke JP, Horne H, Levine DA, Boyd J, Alonso MA, Secord AA, Bernardini MQ, et al: Microarray analysis of early stage serous ovarian cancers shows profiles predictive of favorable outcome. Clin Cancer Res 15: 2448-2455, 2009.

81. Raspaglio G, Petrillo M, Martinelli E, Li Puma DD, Mariani M, De Donato M, Filippetti F, Mozzetti S, Prislei S, Zannoni GF, et al: Sox 9 and Hif- $2 \alpha$ regulate TUBB3 gene expression and affect ovarian cancer aggressiveness. Gene 542: 173-181, 2014.

82. Tanwar PS, Kaneko-Tarui T, Lee HJ, Zhang L and Teixeira JM: PTEN loss and HOXA10 expression are associated with ovarian endometrioid adenocarcinoma differentiation and progression. Carcinogenesis 34: 893-901, 2013

83. Dhillon VS, Shahid M and Husain SA: CpG methylation of the FHIT, FANCF, cyclin-D2, BRCA2 and RUNX3 genes in Granulosa cell tumors (GCTs) of ovarian origin. Mol Cancer 3: 33, 2004.

84. Materna V, Surowiak P, Kaplenko I, Spaczyński M, Duan Z, Zabel M, Dietel M and Lage H: Taxol-resistance-associated gene-3 (TRAG-3/CSAG2) expression is predictive for clinical outcome in ovarian carcinoma patients. Virchows Arch 450: 187-194, 2007.

85. Su HY, Lai HC, Lin YW, Chou YC, Liu CY and Yu MH: An epigenetic marker panel for screening and prognostic prediction of ovarian cancer. Int J Cancer 124: 387-393, 2009.

86. Lum E, Vigliotti M, Banerjee N, Cutter N, Wrzeszczynski KO, Khan S, Kamalakaran S, Levine DA, Dimitrova N and Lucito R: Loss of DOK2 induces carboplatin resistance in ovarian cancer via suppression of apoptosis. Gynecol Oncol 130: 369-376, 2013.

87. Karaca B, Atmaca H, Bozkurt E, Kisim A, Uzunoglu S, Karabulut B, Sezgin C, Sanli UA and Uslu R: Combination of AT-101/cisplatin overcomes chemoresistance by inducing apoptosis and modulating epigenetics in human ovarian cancer cells. Mol Biol Rep 40: 3925-3933, 2013.

88. Lawen A: Apoptosis - an introduction. Bioessays 25: 888-896, 2003.

89. Singh M, Chaudhry P, Fabi F and Asselin E: Cisplatin-induced caspase activation mediates PTEN cleavage in ovarian cancer cells: a potential mechanism of chemoresistance. BMC Cancer 13: 233, 2013.

90. Strathdee G, MacKean MJ, Illand M and Brown R: A role for methylation of the hMLH1 promoter in loss of hMLH1 expression and drug resistance in ovarian cancer. Oncogene 18: 2335-2341, 1999. 